\title{
Association of Adolescent Smoking with Maternal Smoking
}

\author{
Hideko Morikawa1*, Manabu Akahane1, Masahiro Yamada', Tomoaki Imamura1 \\ ${ }^{1}$ Department of Public Health, Health Management and Policy, Nara Medical University School of Medicine, \\ Nara, Japan \\ ${ }^{2}$ Katsuragi Public Health Office and Healthcare Center, Nara Prefectural Government \\ Email: "gaiadeko@naramed-u.ac.jp
}

Received 10 March 2014; revised 8 May 2014; accepted 19 May 2014

Copyright (C) 2014 by authors and Scientific Research Publishing Inc.

This work is licensed under the Creative Commons Attribution International License (CC BY). http://creativecommons.org/licenses/by/4.0/

c) (i) Open Access

\section{Abstract}

Objective: To determine the effect of family smoking habits on adolescent smoking experience for information for anti-smoking strategies. Subjects and Methods: We analyzed data from 4776 junior high school students and 5047 high school students responding to the "Survey on Prevention of Life-Style Related Diseases of Children" conducted in Nara Prefecture of Japan in 2004. The chi-square test determined the odds ratios (ORs) for smoking experience rates of the two groups of students according to the smoking habits of their fathers, mothers, older brothers, and older sisters. Logistic regression analysis was also performed for smoking experience according to school year, sex, and family smoking habit. Results: The OR for smoking in junior high school students with a father as the only smoking family member against all other cases was 0.60 , and the OR with a mother as the only smoking family member was 2.50 . The OR with a smoking father against cases with no smoking family members was 1.23 , and the $\mathrm{OR}$ with a smoking mother against cases with no smoking family members was 3.50. The OR for smoking in high school students with a father as the only smoking family member against all other cases was 0.76 , and the OR with a mother as the only smoking family member was 2.66 . The OR with a smoking father against cases with no smoking family members was 1.59 , and the OR with a smoking mother against cases with no smoking family member was 3.26. All these ORs showed significance. Conclusion: Maternal smoking was associated with a particularly high risk of smoking experience in junior high and high school students. Prevention of maternal smoking should be given high priority to reduce smoking rates in adolescents.

\section{Keywords}

Adolescence, Smoking, Mother, Father

\footnotetext{
*Corresponding author.
} 


\section{Introduction}

Adolescent smoking significantly affects health [1], and smoking is illegal in Japan under the age of 20 years [2]. As adolescent smoking may cause future health issues, it has significant implications for national health economics [3], thus thoroughly implementing adolescent smoking prevention measures are necessary. The adult smoking rates in Japan in 2004 were $43.3 \%$ in males and $12.0 \%$ in females [4]. The rates of smoking experience in third-year high school students in Japan were reportedly $42.0 \% \pm 0.7 \%$ for males and $27.0 \% \pm 0.7 \%$ for females [5]. The Japanese government has serious concern about these rates and aims to decrease the smoking rate of high school students to zero by 2022 as a national health promotion achievement goal [6]. In order to achieve this, analysis of the factors contributing to adolescent smoking is necessary [7]. Those factors are largely divided into internal factors such as depression, anger, anxiety, and fatigue as set out by Whalem et al. [8], and external factors such as academic success, socioeconomic status, family's economic condition, parental habits, and peer habits as set out by Carvajal et al. [9]. Numerous studies have been conducted on the impact of parental smoking, which is recognized as an important external factor for adolescent smoking ([5] [10] [11]). Otten et al. [10] stated that smoking cessation by parents was the best measure to prevent smoking in junior high and high school students. Osaki et al. [5] reported that the decrease in the adolescent smoking rate in Japan since 2000 was significantly attributable to the decrease in the smoking rate of male family members (father, older brother) in particular, and proposed that the impact of maternal smoking should be carefully determined also. Thus, this study aimed to analyze the effects of maternal smoking on the risk of adolescent smoking to provide further information for anti-smoking strategies to prevent smoking in young people.

\section{Subjects and Methods}

This study analyzed data from the "Survey on Prevention of Life-Style Related Diseases of Children [12]" conducted by Nara Prefecture in 2004. Questionnaires were distributed to 4776 first- to third-year students in 20 junior high schools and 5047 first- to third-year students in 15 prefectural high schools. There were 4257 valid responses from junior high school students and 4656 from high school students. The survey comprised 58 items, including questions on lifestyle, physical condition, smoking habit, and alcohol consumption.

This study extracted data related to smoking, as well as basic characteristics such as sex, number of family members, and family structure. Respondents who had experienced smoking once or more were defined as having smoking experience. Respondents who have one or more smoking family member were defined as having a smoking family member. The smoking habits of the respondent's father, mother, older brother and older sister were also determined in the survey. Any other family members who smoked were included as "other family members." All data in this study were anonymized. This study was conducted with the approval of the Ethics Committee of Nara Medical University (authorization code: 822).

\section{Statistical Analysis}

1) First of all, in order to clarify the group characteristics of the subjects in this study, the family smoking habit and the number of single smokers in the family were shown separately for junior high and high school students and for with and without smoking experience. The following cross-tabulation tables were also prepared based on this data.

2) Data were cross-tabulated and the chi-square test was used to determine associations between the smoking experience rates of junior high and high school male and female students and the smoking habits of their family members.

3) The "father smokes" case in this survey includes both the case that "only father smokes" case and the case that "father smokes with other family members." In order to analyze the impact of smoking by family members, new variables were set for the case where only father smokes, the case where only mother smokes, the case where only older brother smokes, and the case where only older sister smokes so that the cases where the only one family member smokes may be separated from the case where several family members smoke. Then data were cross-tabulated and the chi-square test was used to determine associations between the smoking experience rates of junior high and high school male and female students and the smoking habits of their family members to obtain odds ratios (ORs).

4) Logistic regression analysis was performed for the association between the smoking experience rates of ju- 
nior high and high school students and their school year, sex, and family smoking habit. The dependent variables were the smoking experience of junior high and high school students, and the covariates were school year, sex, "father smokes," "mother smokes," “older brother smokes,” and "older sister smokes."

5) Each data were analyzed using SPSS ver. 20 for Windows.

\section{Results}

Table 1 presents the numbers of junior high and high school students with smoking experience and the numbers in their family who smoked. Of 4257 junior high school students, 540 (329 male, 211 female) had smoking experience. Of these, 293 had smoking fathers, of whom 141 were the only smokers in the family, and 198 had smoking mothers, of whom 54 were the only smokers in the family. Of 4656 high school students, 947 students (655 male, 292 female) had smoking experience. Of these, 316 had smoking fathers, of whom 154 were the only smokers in the family, and 171 had smoking mothers, of whom 62 were the only smokers in the family. Of 8913 junior high school and high school students in total, 1263 had smoking mothers, of whom 383 mothers were the only smokers in the family.

Table 1. Junior high school students with smoking experience and smoking habits of family members. High school students with smoking experience and smoking habits of family members.

\begin{tabular}{|c|c|c|c|c|c|}
\hline School type & Smoking experience & Family smoking & Total & Male & Female \\
\hline \multirow{12}{*}{$\begin{array}{c}\text { Junior high } \\
\text { school students } \\
\mathrm{n}=4257\end{array}$} & \multirow{6}{*}{$\begin{array}{l}\text { Yes } \\
540\end{array}$} & Father smokes & $293(141)$ & $182(92)$ & $111(49)$ \\
\hline & & Mother smokes & $198(54)$ & $113(31)$ & $85(23)$ \\
\hline & & Older brother smokes & $69(19)$ & $40(10)$ & $29(9)$ \\
\hline & & Older sister smokes & $45(3)$ & $24(2)$ & $21(1)$ \\
\hline & & Another family member smokes & 202 & 120 & 82 \\
\hline & & None smokes & 121 & 74 & 47 \\
\hline & \multirow{6}{*}{$\begin{array}{c}\text { No } \\
3717\end{array}$} & Father smokes & $1816(1374)$ & 932 (717) & $884(657)$ \\
\hline & & Mother smokes & $528(159)$ & 258 (69) & $270(90)$ \\
\hline & & Older brother smokes & $157(55)$ & $65(24)$ & $92(31)$ \\
\hline & & Older sister smokes & $53(14)$ & $24(7)$ & $29(7)$ \\
\hline & & Another family member smokes & 684 & 334 & 350 \\
\hline & & None smokes & 1431 & 719 & 712 \\
\hline \multirow{12}{*}{$\begin{array}{l}\text { High school } \\
\text { students } \\
\mathrm{n}=4656\end{array}$} & \multirow{6}{*}{$\begin{array}{l}\text { Yes } \\
947\end{array}$} & Father smokes & $316(154)$ & $157(77)$ & 159 (77) \\
\hline & & Mother smokes & $171(62)$ & $102(40)$ & $69(22)$ \\
\hline & & Older brother smokes & $113(28)$ & $60(13)$ & $53(15)$ \\
\hline & & Older sister smokes & $63(8)$ & $22(2)$ & $41(6)$ \\
\hline & & Another family member smokes & 429 & 331 & 98 \\
\hline & & None smokes & 266 & 192 & 74 \\
\hline & \multirow{6}{*}{$\begin{array}{c}\text { No } \\
3709\end{array}$} & Father smokes & $1544(1263)$ & 735 (552) & 809 (711) \\
\hline & & Mother smokes & $366(108)$ & $175(50)$ & $191(58)$ \\
\hline & & Older brother smokes & $281(95)$ & $129(46)$ & $152(49)$ \\
\hline & & Older sister smokes & $90(17)$ & $32(5)$ & $58(12)$ \\
\hline & & Another family member smokes & 480 & 278 & 202 \\
\hline & & None smokes & 1746 & 815 & 931 \\
\hline
\end{tabular}

Numbers in parenthesis represent the number of sole family members who smoked. 
Table 2 shows the ORs (95\%CIs) calculated from cross-tabulation for the association between the smoking experience of junior high and high school students and smoking habits of their family members. The OR for smoking experience in junior high school students with a smoking father was 1.23 and with a smoking mother was 3.50. Junior high school students showed a significantly higher smoking experience rate if they had a smoking mother compared with any other family groups. The ORs for smoking experience in high school students with a smoking father was 1.59 and with a smoking mother was 3.26. Those with a smoking mother showed a significantly higher smoking experience rate than the other groups.

Table 3 shows the ORs for smoking experience among junior high and high school students with a single smoker in the family. Analysis of the junior high school students showed the OR for smoking experience with a father as the only smoking family member was 0.60 , and with a mother as the only smoking family member was 2.50. While the group with a father as the only smoking family member showed a significantly lower smoking experience rate than the other groups, the group with a mother as the only smoking family member showed a significantly higher smoking experience rate. Analysis of high school students showed the OR for smoking experience with a father as the only smoking family member was 0.76 , and with a mother as the only smoking family member was 2.66 . While the group with a father as the only smoking family member showed a significantly lower smoking experience rate than the other groups, the group with a mother as the only smoking family member showed a significantly higher smoking experience rate.

Table 4 shows ORs obtained from logistic regression analysis of the smoking experience rates of junior high and high school students, according to school year, sex, and family smoking habit. Analysis of junior high school students showed the OR for smoking experience with a mother as a smoking family member was 3.24 and with a father as a smoking family member was 0.96 . Thus, the smoking habits of the mother were significantly related to the smoking experience rate of junior high school students. Analysis of high school students showed the OR for smoking experience with a mother as a smoking family member was 2.62 and with a father as a smoking family member was 1.27 . Thus, the smoking habits of both the father and mother were significantly related to the smoking experience rate of high school students.

\section{Discussion}

The results of this study indicated that a maternal smoking habit had a particularly significant effect on increasing the risk of smoking in junior high and high school students. However, the results also indicated that having a father as the only family member who smoked had a significant effect in decreasing the risk of smoking in junior high and high school students.

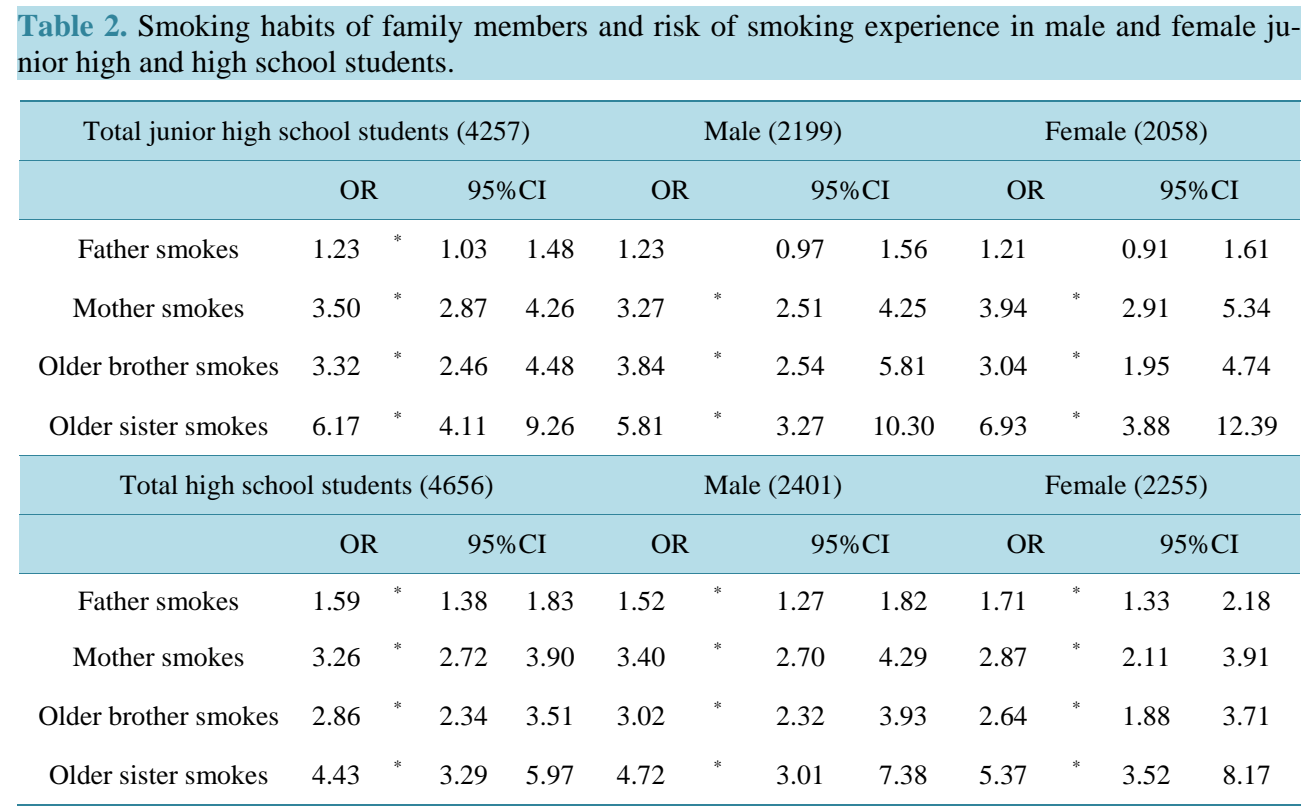

${ }^{*} \mathrm{P}<0.05$; chi-square test; OR, odds ratio; CI, confidence interval. 
Table 3. Sole family member who smoked and risk of smoking experience in male and female junior high and high school students.

\begin{tabular}{|c|c|c|c|c|c|c|c|c|c|c|c|c|}
\hline \multicolumn{5}{|c|}{ Total junior high school students } & \multicolumn{4}{|c|}{ Male } & \multicolumn{4}{|c|}{ Female } \\
\hline & \multicolumn{2}{|c|}{ OR } & \multicolumn{2}{|c|}{$95 \% \mathrm{CI}$} & \multicolumn{2}{|c|}{ OR } & \multicolumn{2}{|c|}{$95 \% \mathrm{CI}$} & \multicolumn{2}{|c|}{ OR } & \multicolumn{2}{|c|}{$95 \% \mathrm{CI}$} \\
\hline Only father smokes & 0.60 & $*$ & 0.49 & 0.74 & 0.62 & ${ }^{*}$ & 0.48 & 0.81 & 0.55 & ${ }^{*}$ & 0.39 & 0.76 \\
\hline Only mother smokes & 2.50 & * & 1.81 & 3.46 & 2.72 & * & 1.75 & 4.22 & 2.42 & * & 1.49 & 3.92 \\
\hline Only older brother smokes & 2.43 & * & 1.43 & 4.12 & 2.41 & * & 1.14 & 5.09 & 2.61 & * & 1.23 & 5.56 \\
\hline Only older sister smokes & 1.48 & & 0.42 & 5.16 & 1.63 & & 0.34 & 7.87 & 1.25 & & 0.15 & 10.22 \\
\hline Only father smokes & 0.76 & * & 0.64 & 0.89 & 0.73 & * & 0.60 & 0.90 & 0.79 & & 0.60 & 1.05 \\
\hline Only mother smokes & 2.66 & * & 1.95 & 3.63 & 2.68 & * & 1.79 & 4.03 & 2.68 & * & 1.61 & 4.44 \\
\hline Only older brother smokes & 1.99 & * & 1.39 & 2.84 & 1.90 & * & 1.20 & 3.01 & 2.12 & * & 1.17 & 3.82 \\
\hline Only older sister smokes & 2.79 & ${ }^{*}$ & 1.33 & 5.86 & 3.22 & & 0.98 & 10.58 & 3.41 & * & 1.27 & 9.16 \\
\hline
\end{tabular}

${ }^{*} \mathrm{P}<0.05$.

Table 4. Logistic regression analysis of smoking in high school students and smoking habits of family members.

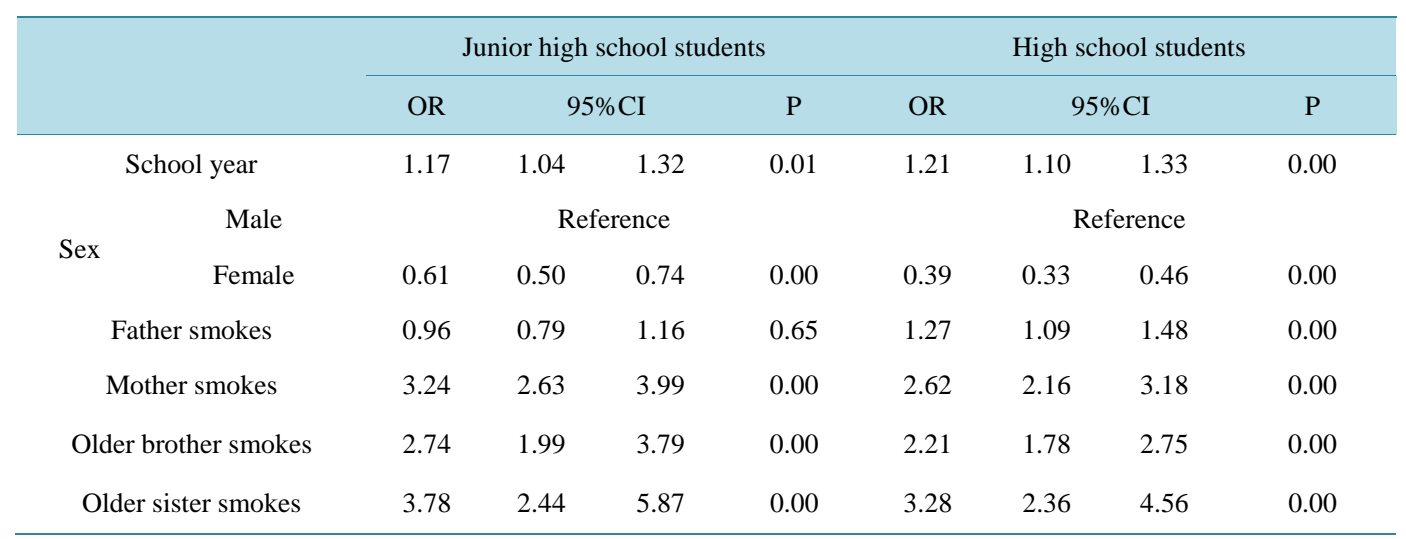

This study analyzed the data of the smoking experience and the family smoking habits of 4257 junior high school students and 4656 high school students obtained from a survey conducted by Nara Prefecture in 2004. The subject schools in this data were extracted from all 39 municipalities of Nara Prefecture to minimize the impact of selection bias. The regional characteristics of Nara Prefecture need to be taken into consideration. Laaksonen et al. [13] reported that the smoking rate varies according to socioeconomic factors, such as education, occupation, income, home ownership, and economic deprivation.

Mansouri et al. [14] reported the familial aggregation of smoking and Schuck et al. [15] reported the smoking contagion across family. This study revealed that maternal smoking had a significantly higher impact than paternal smoking on the smoking experiences rates of adolescents in Japan. With regard to the significant impact of maternal smoking on adolescent smoking, Osaki et al. [5] indicated that although maternal smoking rates were lower than paternal rates, the relative risk of smoking in children with a mother who smoked was much higher. As paternal smoking rates are decreasing, but not maternal rates, maternal smoking is an important issue regarding smoking in young people. Junior high and high school students with a mother as the only smoking family member showed ORs for smoking experience of 2.50 and 2.66, respectively, and were significantly higher than in groups with a father as the only smoking family member, showing the higher impact of maternal smoking on the smoking experience of these school students. Rudatsikira et al. [16] conducted a cross-sectional survey within a global framework on Mongolian teenagers in 2003. This survey dealt with the exposure of children to environmental tobacco smoke from parents and others, and made no reference to the impact of family smoking on the smoking experience of teenagers. Siahpush et al. [17] investigated smoking rates in single 
mothers in Australia with an adolescent child and found a high rate of 44.0\% (37.1 - 50.9\%). However, they stated nothing about the effects of maternal smoking on the smoking experience of junior high and high school students.

\section{Study Limitations}

1) The smoking habits of family members were examined but this study did not investigate the effect of the amount of smoking of family members.

2) This study did not analyze the impact of social environmental factors because the questionnaire did not include questions about the occupation of their father or mother.

3) It was also not possible to analyze the effect of having an older brother or sister as the only smoking family member because the number of subjects was too small.

\section{Conclusions}

1) This study revealed that maternal smoking had a significant impact on the smoking experience of junior high and high school students.

2) This indicates the need for placing a high priority on smoking prevention measures for mothers who have an adolescent child and for women who are expected to have a child in future.

\section{Acknowledgements}

We thank Y. Miyake and M. Matsumura for their assistance in the statistical analyses.

\section{References}

[1] (2013) WHO Report on the Global Tobacco Epidemic 2013. http://apps.who.int/iris/bitstream/10665/85380/1/9789241505871_eng.pdf?ua=1

[2] (1990) Act on Prohibition of Smoking by Minors. Act No. 33. http://law.e-gov.go.jp/htmldata/M33/M33HO033.html

[3] Warner, K.E., Hodgson, T.A. and Carrol, C.E. (1999) Medical Costs of Smoking in the United States: Estimates, Their Validity, and Their Implications. Tabacco Control, 8, 290-300. http://dx.doi.org/10.1136/tc.8.3.290

[4] Ministry of Health, Labor and Welfare (2004) National Health and Nutrition Survey Heisei. http://www.nosmoke55.jp/action/1208eirin kenkounippon21 02tobacco.pdf

[5] Osaki, Y., Tanihata, T. and Ohida, T. (2008) Decrease in the Prevalence of Smoking among Japanese Adolescents and Its Possible Causes: Periodic Nationwide Cross-Sectional Surveys. Environmental Health and Preventive Medicine, 13, 219-226. http://dx.doi.org/10.1007/s12199-008-0033-1

[6] Ministry of Health, Labor and Welfare (2004) Section 3. Measures against Lifestyle-Related Diseases through "Health Japan 21" and Promotion of "Shokuiku (Food and Nutrition Education)". Healthy Japan 21. www.mhlw.go.jp/english/wp/wp-hw2/

[7] Honda, T. and Fukusima, R. (2005) Factors Associated with the Smoking Behavior of University Students. http://hdl.handle.net/11094/9974.201309.22

[8] Whalen, C.K., Jamner, L.D., Henker, B. and Delfino, R.J. (2001) Smoking and Moods in Adolescents with Depressive and Aggressive Dispositions: Evidence from Surveys and Electronic Diaries. Health Psychology, 20, 99-111. http://dx.doi.org/10.1037/0278-6133.20.2.99

[9] Carvajal, S.C., Hanson, C., Downing, R. and Coyle, K.K. (2004) Theory-Based Determinants of Youth Smoking: A Multiple Influence Approach. Journal of Applied Social Psychology, 34, 59-84. http://dx.doi.org/10.1111/j.1559-1816.2004.tb02537.x

[10] Otten, R., et al. (2007) Parental Smoking and Adolescent Smoking Stages: The Role of Parents' Current and Former Smoking, and Family Structure. Journal of Behavioral Medicine, 30, 143-154. http://dx.doi.org/10.1007/s10865-006-9090-3

[11] White, J. (2012) The Contribution of Parent-Child Interactions to Smoking Experimentation in Adolescence: Implications for Prevention. Health Education Research, 27, 46-56. http://dx.doi.org/10.1093/her/cyr067

[12] Medical Treatment Division of Nara Prefecture (2004) Report of Prevention Disease of Child Lifestyle Investigation at Nara.

[13] Laaksonen, M., Rahkonen, O., Karvonen, S. and Lahelma, E. (2005) Socioeconomic Status and Smoking. Analysing Inequalities with Multiple Indicators. European Journal of Public Health, 15, 262-269. 
http://dx.doi.org/10.1093/eurpub/cki115

[14] Mansouri, A., Alvandi, I., Monhammmad, K., Zeraati, H. and Fotouhi, A. (2012) The Familial Aggregation of Cigarette Smoking in Kish, Iran. Iranian Red Crescent Medical Journal, 14, 158-163.

[15] Schuck, K., Otten, R., Engels, R.C., Barker, E.D. and Kleinjan, M. (2013) Bidirectional Influences between Parents and Children in Smoking Behavior: A Longitudinal Full-Family Model. Nicotine \& Tabacco Research, 15, 44-51. http://dx.doi.org/10.1093/ntr/nts082

[16] Rudatsikira, E., Siziya, S., Dondog, J. and Muula, A.S. (2007) Prevalence and Correlate of Environmental Tobacco Smoke Exposure among Adolescents in Mangolia. Indian Journal of Pediatrics, 74, 1089-1093. http://dx.doi.org/10.1007/s12098-007-0203-y

[17] Siahpush, M., Borland, R. and Scollo, M. (2002) Prevalence and Socio-Economic Correlates of Smoking among Lone Mother in Australia. Australian and New Zealand Journal of Public Health, 26, 132-135. http://dx.doi.org/10.1111/j.1467-842X.2002.tb00905.x 